\title{
PENGARUH KUALITAS PRODUK TERHADAP KEPUTUSAN KONSUMEN MEMBELI MOBIL MEREK TOYOTA AGYA DI KOTA PALU (PT. HADJI KALLA)
}

\author{
RIZCKY ARDIANSYAH \\ ROSIDA P. ADAM \\ H. BAKRI \\ Jurusan Manajemen, Fakultas Ekonomi, Universitas Tadulako \\ email : ryczkyardiansyah152@yahoo.com
}

\begin{abstract}
The objective of the research is to find out and analyze the influence of product quality on decision-making, both simultaneously and partially. The research is verificative. The sample involves consumers of Agya car at PT. Hadji Kalla. The analysis tool used is multiple linear regression analysis. The result of regression equation from the study is $-2.887+0,237 X_{1}+0,220 X_{2}$ $+0,217 X_{3}+0,319 X_{4}+0,166 X_{5}+0,418 X_{6}+0,140 X_{7}$. Product Quality partially has significant to decision-making.
\end{abstract}

Keywords: quality products, consumer decision

\begin{abstract}
Abstrak
Tujuan dari penelitian ini adalah untuk mengetahui dan menganalisis pengaruh Kualitas Produk keputusan menandai baik secara simultan maupun parsial. Penelitian ini merupakan penelitian verifikatif. sampel adalah konsumen Of Agya di PT. Hadji Kalla. Alat analisis yang digunakan adalah beberapa analisis regresi linear. Hasil persamaan regresi dari penelitian ini adalah $-2,887+$ $0.237 \mathrm{X} 1+0,220 \mathrm{X} 2+0,217 \mathrm{X} 3+0,319 \mathrm{X} 4+0,166 \mathrm{X} 5+0,418 \mathrm{X} 6+0,140 \mathrm{X} 7$. Kualitas produk parsial memiliki signifikan untuk pembuatan keputusan.
\end{abstract}

Kata Kunci :KualitasProduk, Keputusan Konsumen.

\section{PENDAHULUAN}

Perkembangan industri otomotif dunia mengalami peningkatan dari tahun ke tahun, mulai dari kendaraan roda dua sampai roda empat. Perusahaan otomotif dunia saling berlombalomba untuk mendapatkan respon positif dari para konsumen. Berbagai cara mereka lakukan untuk menarik minat konsumen dengan cara menawarkan desain interor dan eksterior yang digunakan sampai dengan kecanggihan teknologi yang dipakai di mobil tersebut.

Bisnis Transportasi roda empat sangat kompetitif saat ini, hal ini dapat dilihat semakin banyaknya produk beroda empat di pasaran yang membuat konsumen mempunyai banyak pilihan. Hal ini akan membuat permintaan konsumen semakin meningkat. Peningkatan ini menyebabkan harus menambah tingkat produksinya demi memenuhi permintaan.

PT. Hadji Kalla adalah Perusahaan Swasta Nasional yang berpusat di Makassar, yang telah didirikan dengan Akte Nomor 31 (Tiga Puluh Satu) dan dikeluarkan oleh Kantor Notaris Kota Madya Makassar pada Tahun 1952 dan terdiri dari 21 (Dua Puluh Satu) Cabang di Indonesia dan berpusat di Makassar. Nama Perusahaan tersebut sebelumnya adalah NV. Hadji Kalla Trading Coy yang diambil dari Nama Tuan Hadji Kalla dan beliau bertindak sebagai Direktur Utama pada Perusahaan tersebut

Sesuai dengan perkembangan zaman modern yang serba maju menuntut untuk lebih meningkatkan perkembangan perusahaan, dan pada tanggal 21 Januari 1978 telah didirikan sebuah Perusahaan Cabang yang bernama NV. Hadji Kalla Traiding Coy Cabang Palu dengan Surat Kuasa yang diberikan pada tanggal 17 Januari 1978.

Penjualan produk mobil merk Toyota Agya untuk PT. Hadji Kalla dari Tahun 2015 Januari 2016 di bulan Agustus total penjualan mencapai 515 Unit, sedangkan untuk PT. Hasjrat Abadi dari Tahun 2015 Januari - 2016 di bulan Agustus total penjualan mencapai 479 Unit.

Persaingan untuk perusahaan PT Hajji Kalla itu sendiri dalam penjualan mobil merek Toyota Agya ada di perusahaan PT Hasjrat Abadi yang sama-sama menjual produk kendaraan beroda empat oleh Toyota. Tetapi dalam Data jumlah penjualan mobil merek AGYA masih mengungguli 
dalam data penjualan mobil (city car), masih di ungguli oleh perusahaan PT Hajji Kalla dengan jumlah 515unit periode Januari 2014 - Agustus 2015.

Menurut Garvin dalam (Tjiptono, 2005:13) menjabarkan dimensi kualitas ke dalam delapan dimensi yang dapat digunakan sebagai dasar perencanaan strategi terutama bagi perusahaan atau manufaktur yang menghasilkan barang.

Berdasarkan teori di atas kualitas produk yang terdiri dari kinerja yang berkaitan dengan kualitas mesin dari mobil Agya itu sendiri. Fitur dari mobil Agya merupakan aspek dari mobil agya mempunyai spion yang stylish yang dapat melipat secara otomatis. Kehandalan berkaitan dengan kemungkinan mobil Agya berfungsi untuk dipakai mobil Agya mempunyai kehandalan mesin. Kemampuan pelayanan berkaitan dengan tingkat kemampuan pelayanan mobil Agya terhadap spesifikasi yang telah ditetapkan sebelumnya berdasarkan mempunyai pelayanan yang baik.

Daya tahan merupakan salah satu aspek penting karena ketahanan body mobil Agya yang tebal. Perancangan bodi kendaraan aseknya dapat diambil dari mobil Agya mempunyai desain yang mewah. Kualitas persepsi berkaitan dengan mobil Agya mempunyai citra perusahaan yang baik.

Fenomena yang dapat dilihat penggunaan mobil Agya yang ada di Kota Palu, banyak konsumen yang menggunakan mobil Agya sebagai alat transfortasi sehari-hari dalam beraktifitas, mobil Agya ini memiliki ukuran yang sangat kecil, mungil dan sangat nyaman dikendarai. Dari hasil wawancara terhadap 10 konsumen rata-rata memberikan alasan mereka menggunakan mobil Agya karena menilai dan merasakan sejumlah kelebihan yang dimiliki produk tersebut antara lain harga yang murah, dua SRS airbag bagi pengemudi lebih aman ketika kecelakaan, spion elektrik, bagasi yang luas dan bahan bakar yang sangat irit (dalam jarak $20 \mathrm{~km}$ saja hanya memerlukan bbm sebanyak 1liter), selain itu mobil Agya tidak memerlukan lahan parkir yang luas, desain mobil Agya lebih sporty.

Berdasarkan latar belakang di atas adapun tujuan penelitian ini yaitu:

1. Untuk mengetahui pengaruh dari faktor kualitas produk yang terdiri dari Kinerja, Fitur, Kehandalan, Daya Tahan, kemampuan pelayanan, perancangan bodi kendaraan dan Kualitas persepsi. Secara bersama-sama berpengaruh signifikan terhadap keputusan membeli mobil merek Toyota Agya di Kota Palu.

2. Untuk mengetahui pengaruh dari faktor kualitas produk Kinerja berpengaruh terhadap keputusan konsumen membeli mobil merek Toyota Agya di Kota Palu.

3. Untuk mengetahui pengaruh dari faktor kualitas produk Fitur berpengaruh terhadap keputusan konsumen membeli mobil merek Toyota Agya di Kota Palu.

4. Untuk mengetahui pengaruh dari faktor kualitas produk Kehandalan berpengaruh terhadap keputusan konsumen membeli mobil merek Toyota Agya di Kota Palu.

5. Untuk mengetahui pengaruh dari faktor kualitas produk Daya Tahan berpengaruh terhadap keputusan konsumen membeli mobil merek Toyota Agya di Kota Palu.

6. Untuk mengetahui pengaruh dari faktor kualitas produk kemampuan pelayanan berpengaruh terhadap keputusan konsumen membeli mobil merek Toyota Agya di Kota Palu.

7. Untuk mengetahui pengaruh dari faktor kualitas produk perancangan bodi kendaraan berpengaruh terhadap keputusan konsumen membeli mobil merek Toyota Agya di Kota Palu.

8. Untuk mengetahui pengaruh dari faktor kualitas produk Kualitas persepsi berpengaruh terhadap keputusan konsumen membeli mobil merek Toyota Agya di Kota Palu.

\section{KAJIAN LITERATUR DAN PENGEMBANGAN HIPOTESIS Pengertian Produk}

Menurut Kotler dan Amstrong, (2008:266) produk (product) sebagai segala suatu yang ditawarkan kepada pasar agar menarik perhatian, akuisisi, penggunaan, atau konsumsi yang dapat memuaskan suatu keinginan dam kebutuhan.

\section{Pengertian Kualitas Produk}

Menurut Kottler dan Amstrong (2008:273) menjelaskan tentang merek kualitas total (Total Quality Management-TQM) adalah dimana semua orang-orang perusahaan terlibat untuk terus meningkatkan kualitas produk, jasa, dan proses bisnis.

\section{Kerangka Pemikiran}

Pemasaran moderen memerlukan lebih dari sekedar mengembangkan produk yang baik, menawarkan dengan harga menarik, dan membuatnya mudah didapatkan oleh pelanggan sasaran, 
melainkan harus lebih mengarah pada pengetahuan tentang apa sebenarnya yang diinginkan oleh konsumen terhadap produk jasa yang diciptakan dan hendak dipasarkan.

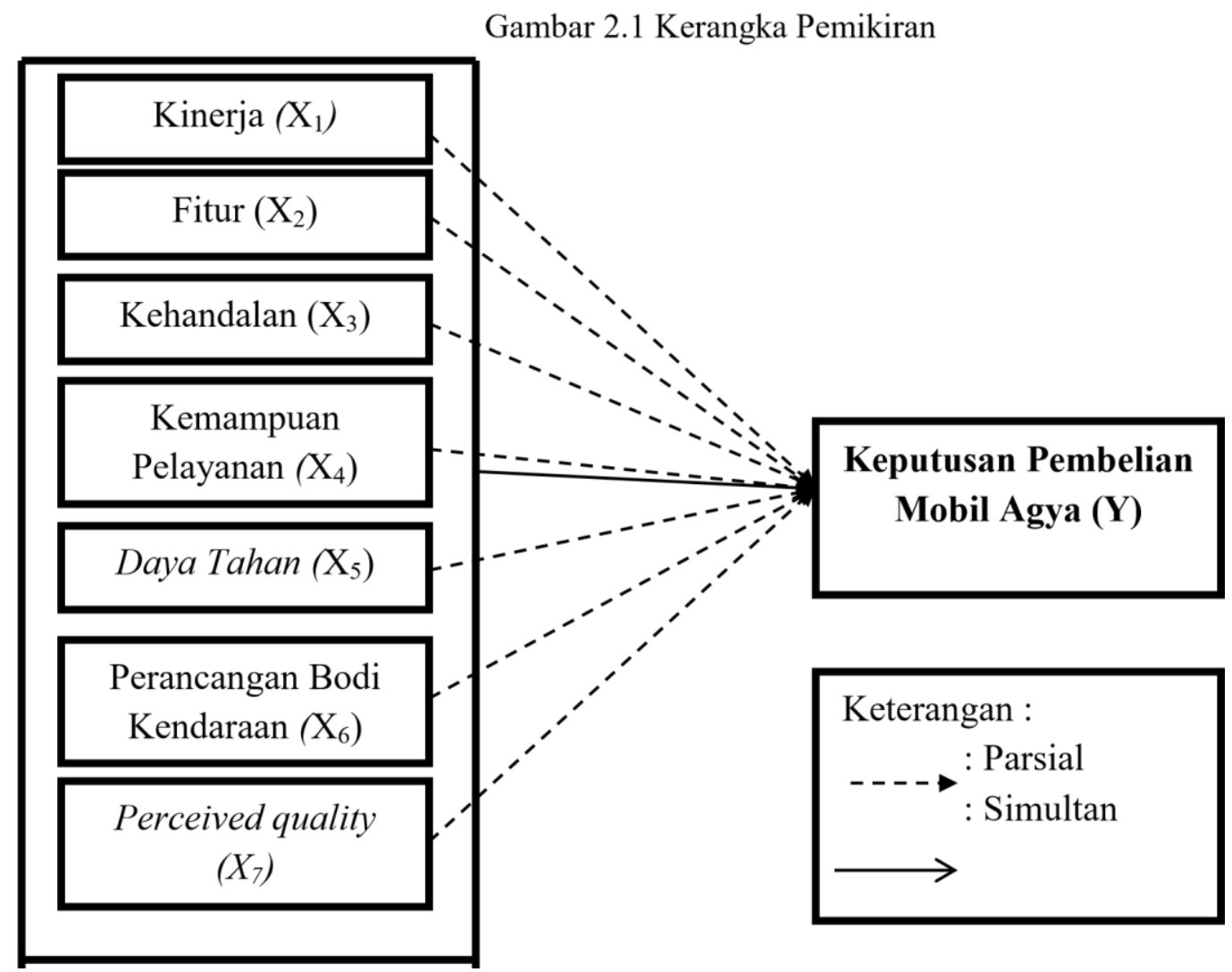

\section{METODE PENELITIAN}

Peneliian ini didesain secara kuantitatif. Adapun teknik-teknik pengumpulan data yang digunakan dalam penelitian adalah sebagai berikut:

1. Kuesioner.

2. Observasi.

3. Wawancara.

Populasi dalam penelitian ini adalah seluruh konsumen yang melakukan pembelian mobil Toyota Agya pada PT. Hadji Kalla di Kota Palu, berdasarkan data yang diperoleh dari PT. Hadji Kalla jumlah konsumen yang melakukan pembelian mobil dalam 2 tahun terakhir periode Januari 2015 Agustus 2016 sebanyak 515.

Sampel yang digunakan dalam penelitian ini yaitu pengaruh kualitas produk terhadap keputusan konsumen membeli mobil merek toyota agya di kota palu. jumlah sampel ditentukan sebagai berikut:

$10 \times 8=80$

Jadi jumlah sampel dalam penelitian ini adalah 80 responden.

Metode analisis data yang digunakan dalam penelitian ini adalah regresi linier berganda. Metode Analisis inimenurut Sugiyono (2010:277) yang sesuai dengan hipotesis yang diajukan adalah:

$$
\mathrm{Y}=\mathrm{a}+\mathrm{b}_{1} \mathrm{X}_{1}+\mathrm{b}_{2} \mathrm{X}_{2}+\ldots \ldots+\mathrm{b}_{\mathrm{n}} \mathrm{X}_{\mathrm{n}}
$$

Dimana:

$$
\begin{array}{ll}
\mathrm{Y} & =\text { Variabel tak bebas (dependen variabel) } \\
\mathrm{a} & =\text { Konstanta (intercept) } \\
\mathrm{X}_{1}-\mathrm{X}_{\mathrm{n}} & =\text { Variabel bebas (independen variabel) } \\
\mathrm{b}_{1}-\mathrm{b}_{\mathrm{n}} & =\text { Besaran yang akan digunakan (koefisien regresi) }
\end{array}
$$

Bila formulasi regresi linear berganda tersebut diaplikasikan dalam penelitian ini, akan diperoleh bentuk persamaan sebagai berikut:

$$
\mathrm{Y}=\mathrm{a}+\mathrm{b}_{1}+\mathrm{X}_{1}+\mathrm{b}_{2} \mathrm{X}_{2}+\mathrm{b}_{3} \mathrm{X}_{3}+\mathrm{b}_{4} \mathrm{X}_{4}+\mathrm{b}_{5} \mathrm{X}_{5}+\mathrm{b}_{6} \mathrm{X}_{6}+\mathrm{b}_{7} \mathrm{X}_{7}
$$




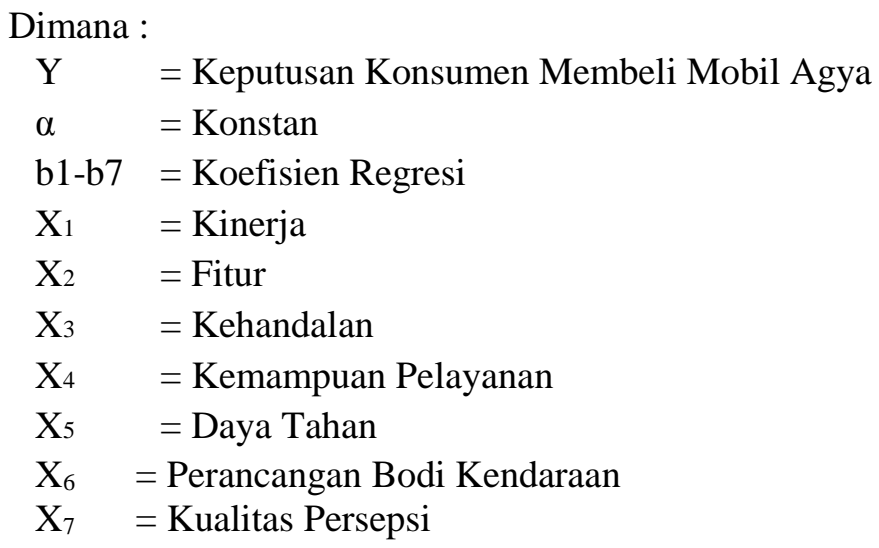

\section{Pengujian Secara Simultan Untuk Hipotesis Pertama ( Uji F)}

Untuk menguji keberartian dari koefisien regresi secara serempak atau simultan digunakan uji-F, dengan bentuk pegujian sebagai berikut:

1. Jika nilai signifikansi, F (Sig. F) atau Probabilitas $\leq(\alpha=0,05)$, maka terbukti semua variabel independen (X) (kinerja, fitur, kehandalan, kemampuan pelayanan, daya tahan, perancangan bodi kendaraan, kualitas persepsi) berpengaruh tidak secara nyata (signifikan) terhadap variabel dependen $(\mathrm{Y})$ (keputusan pembelian konsumen).

2. Jika nilai signifikansi, F (Sig. F) atau Probabilitas $\geq(\alpha=0,05)$, maka terbukti semua variabel independen $(\mathrm{X})$ (kinerja, fitur, kehandalan, kemampuan pelayanan, daya tahan, perancangan bodi kendaraan, kualitas persepsi) berpengaruh serempak secara nyata (signifikan) terhadap variabel dependen (Y) (keputusan pembelian konsumen).

\section{Pengujian Secara Parsial Untuk Hipotesis Kedua Sampai Ke Tujuh}

Untuk menguji pengaruh dari masing-masing faktor bebas secara parsial terhadap faktor terikat (Y) digunakan alat statistik program komputer SPSS 16 dengan kaidah pengambilan keputusan sebagai berikut :

1. Jika nilai signifikansi, $t$ (Sig. t) atau Probabilitas $\leq(\alpha=0,05)$, maka terbukti secara parsial variabel independen $(\mathrm{X})$ (kinerja, fitur, kehandalan, kemampuan pelayanan, daya tahan, perancangan bodi kendaraan, kualitas persepsi) berpengaruh secara nyata (signifikan) terhadap variabel dependen (Y) keputusan pembelian konsumen.

2. Jika nilai signifikansi, $t$ (Sig. $t)$ atau Probabilitas $\geq(\alpha=0,05)$, maka terbukti secara parsial variabel independen $(X)$ berpengaruh secara tidak nyata (signifikan) terhadap variabel dependen (Y) keputusan pembelian konsumen.

\section{HASIL DAN PEMBAHASAN}

\section{Hasil Pengujian Instrument Penelitian}

\section{Hasil Uji Validitas}

Hasil uji validitas instrument dikatakan valid apabila lebih besar dari 0,3 untuk itu hasil validitas instrument disajikan pada tabel berikut:

Tabel 1. Hasil validitas instrument penelitian

\begin{tabular}{|c|c|c|c|c|c|}
\hline No & $\begin{array}{c}\text { Variabel } \\
\text { Penelitian }\end{array}$ & $\begin{array}{c}\text { Indikator } \\
\text { Penelitian }\end{array}$ & $\begin{array}{c}\text { Corrected } \\
\text { Item-Total } \\
\text { Correlation }\end{array}$ & r-Kritis & $\begin{array}{c}\text { Statu } \\
\text { Item }\end{array}$ \\
\hline \multirow{2}{*}{1} & \multirow{2}{*}{ Kinerja } & $\mathrm{X} 1.1$ & 0,719 & 0,3 & Valid \\
\cline { 3 - 6 } & & $\mathrm{X} 1.2$ & 0,561 & 0,3 & Valid \\
\cline { 3 - 6 } & & $\mathrm{X} 1.3$ & 0,655 & 0,3 & Valid \\
\cline { 3 - 6 } & \multirow{2}{*}{ Fitur } & $\mathrm{X} 2.1$ & 0,550 & 0,3 & Valid \\
\cline { 3 - 6 } & & $\mathrm{X} 2.2$ & 0,640 & 0,3 & Valid \\
\cline { 3 - 6 } & & $\mathrm{X} 2.3$ & 0,549 & 0,3 & Valid \\
\hline
\end{tabular}




\begin{tabular}{|c|c|c|c|c|c|}
\hline \multirow[t]{3}{*}{3} & \multirow[t]{3}{*}{ Kehadalan } & X3.1 & 0,680 & 0,3 & Valid \\
\hline & & X3.2 & 0,677 & 0,3 & Valid \\
\hline & & X3.3 & 0,685 & 0,3 & Valid \\
\hline \multirow[t]{3}{*}{4} & \multirow{3}{*}{$\begin{array}{c}\text { Kemampuan } \\
\text { Pelayanan }\end{array}$} & $\mathrm{X} 4.1$ & 0,571 & 0,3 & Valid \\
\hline & & $\mathrm{X} 4.2$ & 0,552 & 0,3 & Valid \\
\hline & & $\mathrm{X} 4.3$ & 0,459 & 0,3 & Valid \\
\hline \multirow[t]{3}{*}{5} & Daya Tahan & $\mathrm{X} 5.1$ & 0,625 & 0,3 & Valid \\
\hline & & $\mathrm{X} 5.2$ & 0,503 & 0,3 & Valid \\
\hline & & $\mathrm{X} 5.3$ & 0,736 & 0,3 & Valid \\
\hline \multirow[t]{3}{*}{6} & \multirow{3}{*}{$\begin{array}{l}\text { Perancangan Bodi } \\
\text { Kendaraan }\end{array}$} & X6.1 & 0,480 & 0,3 & Valid \\
\hline & & X6.2 & 0,470 & 0,3 & Valid \\
\hline & & X6.3 & 0,450 & 0,3 & Valid \\
\hline \multirow[t]{3}{*}{7} & \multirow[t]{3}{*}{ Kualitas Persepsi } & $\mathrm{X} 7.1$ & 0,640 & 0,3 & Valid \\
\hline & & $\mathrm{X} 7.2$ & 0,586 & 0,3 & Valid \\
\hline & & X7.3 & 0,631 & 0,3 & Valid \\
\hline \multirow[t]{3}{*}{8} & \multirow{3}{*}{$\begin{array}{l}\text { Keputusan } \\
\text { Konsumen }\end{array}$} & Y1 & 0,535 & 0,3 & Valid \\
\hline & & Y2 & 0,427 & 0,3 & Valid \\
\hline & & Y3 & 0,555 & 0,3 & Valid \\
\hline
\end{tabular}

Sumber: Lampiran (data di olah kembali)

Berdasarkan hasil uji validitas sebagaimana terurai pada Tabel 1 terbukti bahwa seluruh item pertanyaan yang dituangkan dalam kuesioner penelitian dinyatakan valid. Hal ini disebabkan karena nilai Corrected Item Total Correlation (Korelasi Total) adalah positif dan lebih besar 0,3 $(\mathrm{r} \geq 0,3)$.

\section{Hasil uji realibilitas}

Hasil pengujian reliabilitas untuk masing-masing variabel diperoleh dapat dilihat pada Tabel berikut ini:

Tabel 2 Karakteristik Responden Berdasarkan Jenis Kelamin

\begin{tabular}{|l|l|l|l|l|}
\hline No & Variabel Penelitian & Alpha Cronbach's & Alpha Toleransi & Status Item \\
\hline 1 & Kinerja & 0,785 & 0,6 & Reliabel \\
\hline 2 & Fitur & 0,729 & 0,6 & Reliabel \\
\hline 3 & Kahandalan & 0,822 & 0,6 & Reliabel \\
\hline 4 & Kamampuan pelayanan & 0,707 & 0,6 & Reliabel \\
\hline 5 & Daya tahan & 0,779 & 0,6 & Reliabel \\
\hline 6 & $\begin{array}{l}\text { Perancangan bodi } \\
\text { kendaraan }\end{array}$ & 0,644 & 0,6 & Reliabel \\
\hline 7 & Kualitas persepsi & 0,779 & 0,6 & Reliabel \\
\hline 8 & Keputusan pembelian & 0,689 & 0,6 & Reliabel \\
\hline
\end{tabular}

Berdasarkan table 2. Maka dapat dikatakan kuesioner yang digunakan telah memenuhi syarat reliabilitas karena koefisien alphanya di atas $0,6(\alpha \geq 0,6)$. Sehingga dapat digunakan untuk mengukur variabel yang diteliti di dalam penelitian ini, sebab hasil tersebut menunjukan tingkat konsistensi di atas syarat yang ditentukan.

\section{Deskripsi Responden}

Kuesioner yang disebarkan dalam penelitian ini berjumlah 80 kuesioner dengan subjek penelitiannya adalah responden Masyarakat Kota Palu yang membeli dan menggunakan mobil Agya, karena kuesioner yang dibagikan langsung kepada responden tanpa ada rentang waktu yang lama antara pengisian dan pengembalian kuesioner sehingga resiko tidak di kembalikannya kuesioner tidak ada. 


\section{Jenis Kelamin}

Berdasarkan Tabel 3 dari 80 orang responden, terdapat 29 atau 36,2\% responden Lakilaki dan 51 atau 63,8\% responden Perempuan. Dengan demikian dalam penelitian ini informasi lebih banyak diperoleh dari responden perempuan, mengingat dalam proses pengambilan keputusan ini perempuan lebih banyak menggunakan mobil Agya.

Karakteristik jenis kelamin responden terinci pada tabel 3 di bawah ini:

Tabel 3. Jenis Kelamin

\begin{tabular}{|c|c|c|c|}
\hline No & Jenis Kelamin & Frekuensi & Persentase \\
\hline 1 & Laki-laki & 29 & 36.2 \\
\hline 2 & Perempuan & 51 & 63.8 \\
\hline
\end{tabular}

Berdasarkan Tabel 3 dari 80 orang responden, terdapat 29 atau 36,2\% responden Lakilaki dan 51 atau 63,8\% responden Perempuan. Dengan demikian dalam penelitian ini informasi lebih banyak diperoleh dari responden perempuan, mengingat dalam proses pengambilan keputusan ini perempuan lebih banyak menggunakan mobil Agya.

\section{Usia}

Berdasarkan hasil tanggapan 80 orang responden yang terpilih sebagai sampel dalam penelitian ini, dapat diketahui bahwa segi umur, responden yang membeli dan menggunakan mobil Agya di Kota Palu memiliki umur mulai dari 20 Tahun - 51 Tahun ke atas.

Tabel 4. Usia

\begin{tabular}{|c|c|c|c|}
\hline No & Usia responden & Frekuensi & persentase \\
\hline 1 & $20-30$ Tahun & 11 & 13.8 \\
\hline 2 & $31-40$ Tahun & 22 & 27.5 \\
\hline 3 & $41-50$ Tahun & 24 & 30.0 \\
\hline 4 & $>50$ Tahun & 23 & 28.8 \\
\hline
\end{tabular}

Berdasarkan Tabel 4. di atas menunjukkan bahwa jumlah responden berdasarkan umur di dominasi oleh mereka dari kelompok 41-50 tahun yaitu 24 responden sebesar 30,0\%. Dan kelompok usia yang terkecil yaitu usia 20-30 tahun 11 responden sebesar 13,8\%. Sedangkan Kelompok usia 51 tahun ke atas tidak ada karena kebetulan responden yang terpilih sebagai sampel dalam penelitian ini hanya responden yang memiliki umur 20-50 tahun.

\section{Deskripsi Variabel Penelitian}

Setelah data terkumpul semua, langkah selanjutnya adalah melakukan tabulasi data membuat tingkatan tanggapan konsumen mengenai (kinerja, fitur, kehandalan, kemampuan pelayanan, daya tahan, perancangan bodi kendaraan dan kualitas persepsi). Dimana setiap butiran pertanyaan berentang antara 1 sampai 5 yang di tuju pada 80 responden. Seluruh tanggapan responden akan menentukan hasil dari penelitian ini.

\section{Kinerja (X1)}

Tabel 5 Tanggapan Responden Terhadap Variabel Kinerja (X1)

\begin{tabular}{|c|c|c|c|c|c|c|c|c|c|c|c|}
\hline \multirow{3}{*}{ Indikator } & \multicolumn{8}{|c|}{ Jawaban responden } & \multirow{2}{*}{ Mean } \\
\cline { 2 - 13 } & \multicolumn{3}{|c|}{ SS } & \multicolumn{1}{|c|}{ S } & \multicolumn{2}{|c|}{ RR } & \multicolumn{2}{|c|}{ TS } & \multicolumn{2}{|c|}{ STS } & \\
\cline { 2 - 12 } & $\sum$ & $\%$ & $\sum$ & $\%$ & $\sum$ & $\%$ & $\sum$ & $\%$ & $\sum$ & $\%$ & \\
\hline $\mathrm{X} 1.1$ & 12 & 15,0 & 45 & 56,2 & 20 & 25,0 & 3 & 3,8 & 0 & 0 & 3,8250 \\
\hline $\mathrm{X} 1.2$ & 21 & 26,2 & 41 & 51,2 & 17 & 21,2 & 1 & 1,2 & 0 & 0 & 4,0250 \\
\hline $\mathrm{X} 1.3$ & 21 & 26,2 & 40 & 50,2 & 18 & 22,5 & 1 & 1,2 & 0 & 0 & 4,0125 \\
\hline
\end{tabular}

Berdasarkan Tabel 5 di atas, dapat dilihat penilaian responden terhadap masing-masing indikator variabel kinerja, dari 80 responden yang memberikan penilaian positif yaitu : pengaruh kualitas 
produk terhadap keputusan konsuen membeli mobil merek toyota agya di kota palu, sebagian besar responden menjawab setuju sebanyak 45 atau sekitar 56,2\% dengan nilai mean sebesar 3,8250 atau setuju.

\section{Fitur (X2)}

Tabel 6 Tanggapan Responden Terhadap Variabel Fitur (X2)

\begin{tabular}{|c|c|c|c|c|c|c|c|c|c|c|c|}
\hline \multirow{3}{*}{ Indikator } & \multicolumn{10}{|c|}{ Jawaban Responden } & \multirow{3}{*}{ Mean } \\
\hline & \multicolumn{2}{|c|}{ SS } & \multicolumn{2}{|c|}{$\mathrm{S}$} & \multicolumn{2}{|c|}{$\mathrm{RR}$} & \multicolumn{2}{|c|}{ TS } & \multicolumn{2}{|c|}{ STS } & \\
\hline & $\sum$ & $\%$ & $\sum$ & $\%$ & $\sum$ & $\%$ & $\sum$ & $\%$ & $\sum$ & $\%$ & \\
\hline $\mathrm{X} 2.1$ & 31 & 38,8 & 42 & 52,5 & 6 & 7,5 & 1 & 1,2 & 0 & 0 & 4.2875 \\
\hline X2.2 & 28 & 35,0 & 40 & 50,0 & 10 & 12,5 & 1 & 1,2 & 1 & 1,2 & 4.1625 \\
\hline $\mathrm{X} 2.3$ & 23 & 28,8 & 41 & 51,2 & 14 & 17,5 & 2 & 2,5 & 0 & 0 & 4.0625 \\
\hline
\end{tabular}

Berdasarkan Tabel 6 di atas, dapat dilihat penilaian responden terhadap masing-masing indikator variabel fitur, dari 80 responden yang memberikan penilaian positif yaitu : pengaruh kualitas produk terhadap keputusan konsuen membeli mobil merek toyota agya di kota palu, sebagian besar responden menjawab setuju sebanyak 42 atau sekitar 52,5\% dengan nilai mean sebesar 4.2875 atau setuju.

\section{Kehandalan (X3)}

Tabel 7 Tanggapan Responden Terhadap Variabel Kehandalan (X3)

\begin{tabular}{|c|c|c|c|c|c|c|c|c|c|c|c|}
\hline \multirow{3}{*}{ Indicator } & \multicolumn{8}{|c|}{ Jawabanresponden } & \multirow{2}{*}{ Mean } \\
\cline { 2 - 13 } & \multicolumn{2}{|c|}{ SS } & \multicolumn{2}{|c|}{ S } & \multicolumn{2}{|c|}{ RR } & \multicolumn{2}{|c|}{ TS } & \multicolumn{2}{|c|}{ STS } & \\
\cline { 2 - 13 } & $\sum$ & $\%$ & $\sum$ & $\%$ & $\sum$ & $\%$ & $\sum$ & $\%$ & $\sum$ & $\%$ & \\
\hline $\mathrm{X} 3.1$ & 13 & 16,2 & 55 & 68,8 & 9 & 11,2 & 3 & 3,8 & 0 & 0 & 3.9750 \\
\hline $\mathrm{X} 3.2$ & 18 & 22,5 & 47 & 58,8 & 14 & 17,5 & 1 & 1.2 & 0 & 0 & 4.0250 \\
\hline $\mathrm{X} 3.3$ & 10 & 12,5 & 45 & 56,2 & 22 & 27,5 & 2 & 2,5 & 1 & 1,2 & 3.7625 \\
\hline
\end{tabular}

Berdasarkan Tabel 7 di atas, dapat dilihat penilaian responden terhadap masing-masing indikator variabel kehandalan, dari 80 responden yang memberikan penilaian positif yaitu : pengaruh kualitas produk terhadap keputusan konsuen membeli mobil merek toyota agya di kota palu, sebagian besar responden menjawab setuju sebanyak 55 atau sekitar $68,8 \%$ dengan nilai mean sebesar 3.9750 atau setuju.

\section{Kemampuan Pelayanan (X4)}

Tabel 8 Tanggapan Responden Terhadap Variabel Kemampuan Pelayanan (X4)

\begin{tabular}{|c|c|c|c|c|c|c|c|c|c|c|c|}
\hline \multirow{3}{*}{ Indicator } & \multicolumn{10}{|c|}{ Jawabanresponden } & \multirow{3}{*}{ Mean } \\
\hline & \multicolumn{2}{|c|}{$\mathrm{SS}$} & \multicolumn{2}{|r|}{$\mathrm{S}$} & \multicolumn{2}{|c|}{$\mathrm{RR}$} & \multicolumn{2}{|c|}{ TS } & \multicolumn{2}{|c|}{ STS } & \\
\hline & $\sum$ & $\%$ & $\sum$ & $\%$ & $\sum$ & $\%$ & $\sum$ & $\%$ & $\sum$ & $\%$ & \\
\hline $\mathrm{X} 4.1$ & 30 & 37,5 & 32 & 40,0 & 6 & 7,5 & 12 & 15,0 & 0 & 0 & 4.0000 \\
\hline $\mathrm{X} 4.2$ & 23 & 28,8 & 42 & 52,5 & 6 & 7,5 & 7 & 8,8 & 2 & 2,5 & 3.9625 \\
\hline $\mathrm{X} 4.3$ & 36 & 45,0 & 37 & 46,2 & 1 & 1,2 & 5 & 6,2 & 1 & 1,2 & 4.2750 \\
\hline
\end{tabular}

Berdasarkan Tabel 8 di atas, dapat dilihat penilaian responden terhadap masing-masing indikator variabel kemampuan pelayanan, dari 80 responden yang memberikan penilaian positif yaitu: pengaruh kualitas produk terhadap keputusan konsuen membeli mobil merek toyota agya di kota 
palu, sebagian besar responden menjawab setuju sebanyak 42 atau sekitar 52,5\% dengan nilai mean sebesar 3.9625 atau setuju.

\section{Daya Tahan (X5)}

Tabel 9 Tanggapan Responden Terhadap Variabel Daya Tahan (X5)

\begin{tabular}{|c|c|c|c|c|c|c|c|c|c|c|c|}
\hline \multirow{3}{*}{ Indicator } & \multicolumn{10}{|c|}{ Jawabanresponden } & \multirow{3}{*}{ Mean } \\
\hline & \multicolumn{2}{|c|}{ SS } & \multicolumn{2}{|c|}{ S } & \multicolumn{2}{|c|}{$\mathrm{RR}$} & \multicolumn{2}{|c|}{ TS } & \multicolumn{2}{|c|}{ STS } & \\
\hline & $\sum$ & $\%$ & $\sum$ & $\%$ & $\sum$ & $\%$ & $\sum$ & $\%$ & $\sum$ & $\%$ & \\
\hline X5.1 & 19 & 23,8 & 42 & 52,5 & 5 & 6,2 & 14 & 17,5 & 0 & 0 & 3.8250 \\
\hline $\mathrm{X} 5.2$ & 25 & 31,2 & 26 & 31,5 & 5 & 6,2 & 21 & 26,2 & 3 & 3,8 & 3.6125 \\
\hline $\mathrm{X} 5.3$ & 32 & 40,0 & 33 & 41,2 & 1 & 1,2 & 14 & 17,5 & 0 & 0 & 4.0375 \\
\hline
\end{tabular}

Berdasarkan Tabel 9 di atas, dapat dilihat penilaian responden terhadap masing-masing indikator variabel daya tahan, dari 80 responden yang memberikan penilaian positif yaitu : pengaruh kualitas produk terhadap keputusan konsuen membeli mobil merek toyota agya di kota palu, sebagian besar responden menjawab setuju sebanyak 42 atau sekitar 52,5\% dengan nilai mean sebesar 3.8250 atau setuju.

\section{Perancangan Bodi Kedaraan (X6)}

Tabel 10

Tanggapan Responden Terhadap Variabel Perancangan Bodi Kendaraan (X6)

\begin{tabular}{|c|c|c|c|c|c|c|c|c|c|c|c|}
\hline \multirow{3}{*}{ Indikator } & \multicolumn{10}{|c|}{ Jawabanresponden } & \multirow{2}{*}{ Mean } \\
\cline { 2 - 13 } & \multicolumn{2}{|c|}{ SS } & \multicolumn{2}{|c|}{ S } & \multicolumn{2}{|c|}{ RR } & \multicolumn{2}{c|}{ TS } & \multicolumn{2}{c|}{ STS } & \\
\cline { 2 - 13 } & $\sum$ & $\%$ & $\sum$ & $\%$ & $\sum$ & $\%$ & $\sum$ & $\%$ & $\sum$ & $\%$ & \\
\hline X6.1 & 34 & 42,5 & 29 & 36,2 & 7 & 8,8 & 9 & 11,2 & 1 & 1,2 & 4.0750 \\
\hline X6.2 & 31 & 38,8 & 36 & 45,0 & 6 & 7,5 & 7 & 8,8 & 0 & 0 & 4.1375 \\
\hline X6.3 & 44 & 55,0 & 22 & 27,5 & 4 & 5,0 & 10 & 12,5 & 0 & 0 & 4.2500 \\
\hline
\end{tabular}

Berdasarkan Tabel 10 di atas, dapat dilihat penilaian responden terhadap masingmasing indikator variabel perancangana bodi kendaraan, dari 80 responden yang memberikan penilaian positif yaitu : pengaruh kualitas produk terhadap keputusan konsuen membeli mobil merek toyota agya di kota palu, sebagian besar responden menjawab sangat setuju sebanyak 44 atau sekitar 55,0\% dengan nilai mean sebesar 4.2500 atau setuju.

\section{Kualitas Persepsi(X7)}

Tabel 11 Tanggapan Responden Terhadap Kualitas Persepsi (X7)

\begin{tabular}{|c|c|c|c|c|c|c|c|c|c|c|c|}
\hline \multirow{3}{*}{ Indikator } & \multicolumn{9}{|c|}{ Jawabanresponden } & \multirow{2}{*}{ Mean } \\
\cline { 2 - 13 } & \multicolumn{2}{|c|}{ SS } & \multicolumn{2}{|c|}{ S } & \multicolumn{2}{|c|}{ RR } & \multicolumn{2}{c|}{ TS } & \multicolumn{2}{c|}{ STS } & \\
\cline { 2 - 12 } & $\sum$ & $\%$ & $\sum$ & $\%$ & $\sum$ & $\%$ & $\sum$ & $\%$ & $\sum$ & $\%$ & \\
\hline X7.1 & 24 & 30,0 & 34 & 42,5 & 16 & 20,0 & 5 & 6,2 & 1 & 1,2 & 3.9375 \\
\hline X7.2 & 22 & 27,5 & 37 & 46,2 & 14 & 17,5 & 7 & 8,8 & 0 & 0 & 3.9250 \\
\hline X7.3 & 27 & 33,8 & 33 & 41,2 & 12 & 15,0 & 6 & 7,5 & 2 & 2,5 & 3.9625 \\
\hline
\end{tabular}

Berdasarkan Tabel 11 di atas, dapat dilihat penilaian responden terhadap masingmasing indikator variabel kualitas persepsi, dari 80 responden yang memberikan penilaian positif yaitu : pengaruh kualitas produk terhadap keputusan konsuen membeli mobil merek toyota agya di kota palu, sebagian besar responden menjawab setuju sebanyak 37 atau sekitar 46,2\% dengan nilai mean sebesar 3.9250 atau setuju. 


\section{Hasil Uji Regresi Linear Berganda}

Dalam menjawab permasalahan dan menguji hipotesis dalam penelitian ini digunakan alat analisis statistik regresi linear berganda (Multiple linear regression) dengan menggunakan program SPSS 16. Berdasarkan persamaan regresi linier berganda di atas, dapat dijelaskan bahwa koefisien variabel $\mathrm{X} 1, \mathrm{X} 2, \mathrm{X} 3, \mathrm{X} 4, \mathrm{X} 5, \mathrm{X} 6$ dan $\mathrm{X} 7$ menunjukkan pengaruh positif terhadap keputusan konsumen (Y). Berdasarkan nilai Sig.F yang 0,000 dimana nilai tersebut lebih kecil dari $\alpha(0,05)$, maka variabel-variabel $\mathrm{X} 1, \mathrm{X} 2, \mathrm{X} 3, \mathrm{X} 4, \mathrm{X} 5, \mathrm{X} 6$ dan $\mathrm{X} 7$ memiliki pengaruh yang signifikan terhadap keputusan konsumen. Kemudian untuk nilai beta X1, X2, X3, X4, X5, X6 dan $X 7$ maka dapat diketahui nilainnya $X 1=0,237 ; X 2=0,220 ; X 3=0,217 ; X 4=0,319 ; X 5=0,166$; $\mathrm{X} 6=0,418 ; \mathrm{X} 7=0,140$, yang artinya jika nilai Sig $\mathrm{F}$ (probability) $\leq \alpha=0,05$ maka dapat dikatakan variabel tersebut berpengaruh positif terhadap keputusan konsumen. Untuk lebih jelasnya dapat dilihat pada table 12 di bawah ini:

\section{Pengujian Hipotesis Pertama atau Uji Simultan (Uji F)}

Dari diketahui bahwa nilai Sig $F$ atau probabilitasnya adalah 0.000 , yang artinya bahwa jika nilai sig $\mathrm{F}$ (probability) $\leq \alpha=0,05$, maka dapat diketahui bahwa variabel-variabel X1, X2, X3, X4, X5, X6 dan X7 secara serempak memberikan pengaruh signifikan terhadap keputusan konsumen. Adapun besar pengaruh dari ketujuh variable tersebut ditunjukkan melalui besar $\mathrm{R}^{2}$ yaitu sebesar 0.693 atau $69,3 \%$.

\section{Pengujian Hipotesis Kedua t (Parsial)}

Bahwa besarnya probalitas signifikan variabel kinerja (X1) adalah t sig $0,002<\alpha(0,05)$. Dengan demikian bahwa secara statistik variabel kinerja dalam penilitian ini memberikan pengaruh yang signifikan terhadap keputusan konsumen dalam membeli mobil Toyota Agya di Kota Palu. Adapun besar pengaruh dari variabel tersebut ditunjukkan melalui besar partial yaitu sebesar 0.237.

\section{Pengujian Hipotesis Ketiga (X2).}

Hasil yang diperoleh dalam penelitian ini bahwa besarnya probability signifikasi variabel fitur adalah t sig $0,013<\alpha(0,05)$. Dengan demikian bahwa secara fisik variabel fitur dalam penelitian ini memberikan pengaruh yang signifikan terhadap keputusan konsumen membeli mobil Agya di Kota Palu. Adapun besar pengaruh dari variabel tersebut ditunjukkan melalui besar partial yaitu sebesar 0.220 .

\section{Pengujuan Hipotesis Keempat (X3)}

Hasil yang diperoleh dalam penelitian ini bahwa besarnya probabilitas signifikan fariabel kehandalan (X3) adalah t sig $0,022<\alpha(0,05)$. Dengan demikian bahwa secara statistik variabel kehandalan dalam penelitian ini memberikan pengaruh yang signifikan terhadap keputusan konsumen membeli mobil Agya di Kota Palu. Adapun besar pengaruh dari variabel tersebut ditunjukkan melalui besar partial yaitu sebesar 0.217.

\section{Pengujian Hipotesis Kelima (X4)}

Hasil yang diperoleh dalam penelitian ini bahwa besarnya probability signifikansi variabel kemampuan pelayanan adalah $\mathrm{t}$ sig $0.000<\alpha(0,05)$. Dengan demikian bahwa secara statistik variabel kemampuan pelayanan dalam penelitian ini memberikan pengaruh yang signifikan tehadap kepuasan konsumen membeli mobil Agya di Kota Palu. Adapun besar pengaruh dari variabel tersebut ditunjukkan melalui besar partial yaitu sebesar 0.319 .

\section{Pengujian Hipotesis Keenam (X5)}

Hasil yang diperoleh dalam penelitian ini bahwa besarnya probability signifikansi variabel daya tahan adalah t sig $0.010>\alpha(0,05)$. Dengan demikian bahwa secara statistik variabel daya tahan dalam penelitian ini tidak memberikan pengaruh yang signifikan tehadap keputusan konsumen membeli mobil Agya di Kota Palu. Adapun besar pengaruh dari variabel tersebut ditunjukkan melalui besar partial yaitu sebesar 0.166 . 


\section{Pengujian Hipotesis Ketujuh (X6)}

Hasil yang diperoleh dalam penelitian ini bahwa besarnya probability signifikansi variabel perancangan bodi kendaraan adalah t sig $0.000>\alpha(0,05)$. Dengan demikian bahwa secara statistik variabel perancangan bodi kendaraan dalam penelitian ini tidak memberikan pengaruh yang signifikan tehadap keputusan konsumen membeli mobil Agya di Kota Palu. Adapun besar pengaruh dari variabel tersebut ditunjukkan melalui besar partial yaitu sebesar 0.418.

\section{Pengujian Hipotesis Kedelapan(X7)}

Hasil yang diperoleh dalam penelitian ini bahwa besarnya probability signifikansi variabel kualitas persepsi adalah t sig $0.023<\alpha(0,05)$. Dengan demikian bahwa secara statistik variabel kualitas persepsi dalam penelitian ini memberikan pengaruh yang signifikan tehadap keputusan konsumen membeli mobil Agya di Kota Palu. Adapun besar pengaruh dari variabel tersebut ditunjukkan melalui besar partial yaitu sebesar 0.140 .

\section{KESIMPULAN DAN SARAN}

\section{Kesimpulan}

1. Kualitas produk terdiri dari Kinerja, Fitur, Kehandalan, Daya Tahan, Kemampuan Pelayanan, Perancanga Bodi Kendaraan dan Kualitas persepsi secara bersama-sama berpengaruh signifikan terhadap keputusan konsumen membeli mobil Toyota Agya di Kota Palu.

2. Kinerja berpengaruh signifikan terhadap keputusan konsumen membeli mobil Toyota Agya di Kota Palu.

3. Fitur berpengaruh signifikan terhadap keputusan konsumen membeli mobil Toyota Agya di Kota Palu.

4. Kehandalan berpengaruh signifikan terhadap keputusan konsumen membeli mobil Toyota Agya di Kota Palu.

5. Daya tahan berpengaruh signifikan terhadap keputusan konsumen membeli mobil Toyota Agya di Kota Palu.

6. Kemampuan pelayanan berpengaruh signifikan terhadap keputusan konsumen membeli mobil Toyota Agya di Kota Palu.

7. Perancangan bodi kendaraan berpengaruh signifikan terhadap keputusan konsumen membeli mobil Toyota Agya di Kota Palu.

8. Kualitas persepsi berpengaruh signifikan terhadap keputusan konsumen membeli mobil Toyota Agya di Kota Palu.

\section{Saran}

Adapun saran-saran saran-saran berdasarkan kesimpulan di atas ataupun saran-saran lainnya yang dapat penulis berikan adalah:

1. Kepada pihak perusahaan dalam hal ini adalah semua perusahaan dibidang otomotif terutama mobil, harus terus mengontrol dan mengevaluasi variabel-variabel yang terbukti memberikan pengaruh yang signifikan terhadap keputusan konsumen membeli mobil, agar terjadi peningkatan baik dari segi produktivitas dan efektivitas perusahaan maupun dari segi keuntungan perusahaan. Khusus untuk dimensi kemampuan pelayanan dan perancangan bodi kendaraan, perusahan harus lebih memperhatikan dimensi tersebut agar memberikan pengaruh.

2. Untuk penelitian selanjutnya, diharapkan untuk mencari, menambahkan, atau bahkan mengkombinasikan variabel-variabel pembentuk skeputusan konsumen mobil, agar hasil penelitiannya memberikan kontribusi yang bermakna pada pihak-pihak yang berkepentingan.

3. Kepada pihak-pihak yang berkepentingan diharapkan dapat memberikan saran-saran dan tanggapan untuk penulis dalam penelitian ini.

\section{REFERENSI}

Kotler dan Amstrong. (2008). Pengertian Produk. PT Prehalindo. Jakarta.

Sugiyono. (2007). Metode Penelitian Bisnis. Alfabeta Bandung.

Tjiptono. (2002). Pengertian manajemen pemasaran. Andi Yogyakarta

Ghozali, Imam. 2005. Aplikasi Analisis Multivariate Bagi Program SPSS. Cetakan ke-4, 